\title{
EPA reveals plans to double external grants
}

Washington. Keen to improve the quality of the science it sponsors in universities and elsewhere, the US Environmental Protection Agency (EPA) plans to double spending on grants to outside researchers next year, to $\$ 44$ million.

Most of the additional $\$ 22$ million will pay for environmental research funded jointly with the National Science Foundation (NSF) in four areas of mutual interest: water and wetlands, global change, pollution prevention and social dimensions of environmental issues. The rest of the money will be used for grants in areas of particular interest to EPA, such as indoor air pollution.

Under an agreement signed by the two agencies last week, NSF will take the lead in peer-reviewing both types of grants. The call for proposals is due to go out next month.

EPA hopes the expanded grant programme will strengthen both its ties to academic scientists and its research base. Robert Huggett, the new head of the agency's Office of Research and Development (ORD), says the agency would like to double its funding for extramural grants again in 1996, and to reach $\$ 100$ million by 1997 .

Huggett also hopes that the link with NSF will give greater credibility to EPA's peer-review process, long criticized for its lack of rigour. Indeed, Congress has told NSF to help the agency with its peer-review procedures, and made the release of next year's funding for ORD contingent on a further review of agency research by the National Academy of Sciences.

Huggett says he is familiar with the poor reputation of EPA research from a period he spent on the agency's science advisory board. Now, he says, he is working to remove that stigma and make EPA "the first choice for a young [environmental] scientist or engineer right out of school".

To enlarge the pool of available talent, the agency is also initiating a new graduate fellowship programme. This will fund 100 master's and PhD students in 1995, with a target of 300 students by 1997 . The call for applications for next year's fellowships went out this week.

In his first few months in the job, Huggett has earned high marks for his energy and enthusiasm for reforming EPA science. But he faces formidable institutional obstacles, not least a fundamental conflict between the agency's regulatory mission and its desire to carry out long-term research.

In the past, EPA scientists have been diverted from research projects to provide quick answers whenever regulators need to write a new rule on, for example, clean water or pesticide safety. Huggett says this primary mission will never go away. "ORD exists to support the programme offices," he says. "It does not exist to conduct environmental research for the sake of it."
But he says he also wants to create a more hospitable climate for scientists working on long-term research problems. ORD will now have a dual promotion track, so that bench researchers can advance as quickly as scientists who manage contracts and handle administrative duties.

Some agency scientists who have been doing administrative work will be offered schooling to "get back into the mainstream of science and engineering". And Huggett wants to begin a competitive internal grants programme, also peer-reviewed by NSF, that would allow projects proposed by EPA's own scientists.

Agency officials have made it a goal to increase the amount of long-term research at EPA from the current one-third to a half of the agency's total research budget to half (see Nature 370, 239; 1994).

Perhaps the most visible change within ORD is the restructuring of the office's 12 research laboratories into four 'mega-labs':

two in North Carolina focused on environmental health effects and exposure to those effects; a national risk assessment centre in Washington; and a centre for risk management in Cincinnati, Ohio. The reorganization should be completed by next month.

So far, the reform of EPA science is largely limited to shuffling existing resources. The head of the agency, Carol Browner, has deferred any decisions about closing or consolidating laboratories until 1996. And although more than 250 contractors will become employees, they are mostly laboratory technicians, not scientists.

Huggett has so far been able to find the money he needs for next year's expanded grants programme by 'reprogramming' research funds that had been used to support the regulatory offices. But reaching his target of $\$ 100$ million will almost certainly require additional funds - which the new Congress may be reluctant to provide.

Tony Reichhardt

\section{DNA, sex and the single macaw}

London. Scientists at the University of Oxford are using the polymerase chain reaction (PCR) in the fight to save the world's most endangered bird, the Spix's macaw Cyanopsitta spixii (right), by developing a test to establish the sex of the only Spix's macaw still in the wild.

The species was believed to be extinct in the wild until a single bird was spotted in the arid interior of east-central Brazil in July 1990. The Brazilian government established a Permanent Committee for the Recovery of Spix's Macaw in the mid1980s. This consortium, which includes most holders of captive birds, now plans to release one of the $\mathbf{2 6}$ known captive birds as a mate.

The problem is that no-one knows the sex of the lone wild macaw. According to Martin Kelsey, head of the Americas division at BirdLife International, evidence from field studies suggests that the wild bird is a male. The consortium has therefore decided to release one of the very precious females originally captured from the wild as its chances of survival are higher. The bird is likely to be released in December, when food is most abundant and pair formation is most likely to take place.

Around two-thirds of the world's bird species cannot be sexed visually, so the usual technique is a chromosome squash, using material from the base of a growing feather. This would involve capturing the wild bird, a traumatic experience that the Brazilian government wanted to avoid.

As a result, Richard Griffiths and Bela Tiwari from the Unit of Ecology and Behav-

\section{IMAGE UNAVAILABLE FOR COPYRIGHT REASONS}

iour have turned to PCR to amplify the small amounts of nuclear DNA contained in moulted feathers collected from the jungle. But they also need a marker.

In birds, the female is heterogametic, having one $W$ and one $Z$ chromosome, while the male has two $Z$ chromosomes. Using DNA from chickens, Griffiths and Tiwari identified a $W$-linked sequence which, according to Griffiths, is probably common to all birds.

They focused their search for the marker using a genomic library from the related species, the hyacinth macaw Anodorhynchus hyacinthinus, and isolated a W-linked portion of the parrot genome. The test has been 100 per cent accurate when tested on captive Spix's macaws.

The researchers have also confirmed that the marker is W-linked using Southern blots. "We've got the test. The difficulty is getting enough DNA out of the feathers," says Griffiths. Maggie Verrall 